\title{
Galvanic Corrosion Characteristics of Aluminium Alloy with Group II Metal
}

\author{
Vijayarani $\mathrm{K}^{\mathrm{a}}$, VishnuDevan $\mathrm{M}^{\mathrm{a}}$, and Natarajan $\mathrm{R}^{\mathrm{b}}$. \\ ${ }^{a}$ P.G.\& Research Department of Chemistry, Government Arts college, Karur ,690005,Tamil Nadu. \\ ${ }^{b}$ P.G.\& Research Department of Chemistry, Alagappa Government Arts college, Karaikudi-630003,Tamil Nadu.
}

\begin{abstract}
The Electrochemical behavior of Al -Zn5\% sacrificial anode with selected element (Sr) has been investigated in 3\% sodium chloride solution. Corrosion experiment was mounted to determine the optimal effect of Sr on the efficiencies of the aluminium alloy anodes. The unexposed sample was subjected to micro structure characterization by SEM and XRD techniques. The impedance measurement and microscopic observation confirmed that better activity was realized with Al-Zn-Sr alloy compared with base Al-Zn5\% alloy. The addition of Sr shifts open circuit potential $(\sim 50 \mathrm{mV})$ and corrosion potential $(\sim 60 \mathrm{mV})$ to a negative value. However, the shift is observed as a gradual decrease with Strontium content and 5\% of strontium addition resulted with maximum efficiency (99.46\%). Better electrochemical performance of $\mathrm{Al}-\mathrm{Zn}-\mathrm{Sr} 5 \%$ alloy attributed as due to the presence of fine grains $\mathrm{Al}_{2} \mathrm{Zn}_{3} \mathrm{Sr}_{3}$ and grain boundaries that contains fine $\mathrm{Al}_{2} \mathrm{Zn}_{3} \mathrm{Sr}_{3}$ precipitate. The addition of Sr improves the electrochemical properties of Al90-Zn5-Sr5\% alloy and resulted uniform corrosion due to the presence of fine grains of particles constituent elements with distribution of these particles across the grain boundaries. The electrode is very efficient in the view of economical point of view and can be prepared conveniently as a conventional hanging electrodes, tolerable in very aggressive media and high efficient under high current load.
\end{abstract}

Keywords: alkaline earth metal, aluminium alloy, efficiency, sacrificial anode and strontium.

\section{Introduction}

Corrosion is the deterioration of materials with its environment and it can be mitigated by various techniques. Cathodic protection is one of the techniques that are employed mainly in industries and marine environments to control corrosion. Cathodic protection is greatly employed to protect oil pipelines, marine and some industrial structures. In this system, particularly sacrificial anode system, electric current is applied by using dissimilar metals with the driving voltage created by the potential generation between the two metals in an electrolyte system. The electrochemical behaviour of sacrificial anode materials is of vital importance for the reliability and efficiency of cathodic protection systems [1].

Generally, metals such as aluminium, zinc and magnesium are employed as anode materials in sacrificial cathodic protection systems. The limitation of usage of magnesium based alloy system is its low efficiency, which gives rise to loss of substantial parts of the required current capacity. It is affirmed that aluminium is the most preferred sacrificial anodes for controlling and preventing corrosion in marine environments. Aluminium anodes are also favoured over zinc anodes for the cathodic protection of offshore structures especially in deep water exploration because they are lighter and less expensive. Evaluation of the performance of aluminium anodes is necessary to achieve the most cost-effective sacrificial cathodic protection design. The usefulness of pure aluminium as an anode material in seawater is reduced significantly due to the formation of a protective oxide film, which limits both its current and potential output. In order to improve the efficiency of aluminium anodes they are typically alloyed with other elements to encourage depassivation (breakdown of the oxide film) and/or shift the operating potential of the metal to a more electronegative direction. The alloying elements used to accomplish this are referred as depassivators and modifiers. Modifiers that have been used in practice include zinc, magnesium, barium, and cadmium. Also, the depassivators commonly used are indium, mercury, tin and rarely gallium, titanium and thallium. However, these metals are highly toxic in marine environment. Hence, the metal modifier used should possess eco-friendly as well as good activation for an improved performance as sacrificial anodes.

Most of the efforts in this field were carried out using aluminium rich zinc sacrificial anodes and the concentration of zinc in aluminium alloy sacrificial anodes has been optimized to $5 \mathrm{wt} \%$ due to high improvement in metallurgical and electrochemical properties of the alloy through the formation of $\beta$-phase [2] Addition of alloying elements like tin and indium shifts the potential of the anode in the negative direction and helps in keeping the anode active [3]. Modification of $\mathrm{Al}+5 \% \mathrm{Zn}$ alloy anode is essential due to non-columbic loss and low galvanic efficiency [4] The base alloy chosen for the present work is $\mathrm{Al}+5 \% \mathrm{Zn}$, which has been

National Conference on Current Advancements in Physics $3^{\text {rd }} \& 4^{\text {th }}$ February 2017 49 | Page Department of Physics, St. John's College, Palayamkottai-627 002, Tamilnadu, India. DOI 10.9790/4861-17002024957 
proved to be the most suitable and efficient material for cathodic protection application[5]. Considering Al- $\mathrm{Zn}$ binary system, zinc is concentrated in interdentritic or grain boundaries and several theories has been proposed to explain the influence of zinc towards activation of dissolution of $\mathrm{Al}$ in chloride aqueous environment [6]. 5\% $\mathrm{Zn}$ is the optimized concentration as a second major element with aluminum for the newly developed aluminum alloy used in the cathodic protection application in saline water environment [2,7-11].

Extensive studies on the surface modification of Al alloys by binary or ternary have been reported[1217]. Hence, the uniform and homogeneous distribution of other metal on aluminium alloy effectively suppresses the formation of passive $\mathrm{Al}_{2} \mathrm{O}_{3}$ on the $\mathrm{Al}$ alloy anode systems, which in turn activates the anode i.e., alloying of third metal on aluminium-zinc alloy.

To the best of our knowledge, the effects of addition of alkaline earth metal particularly strontium has not been studied as a modifier in Al-Zn binary base alloy. Herein, we have made an attempt to investigate the dissolution behaviour of Al-Zn-Sr ternary alloy and results are compared with Al-Zn binary base alloy. In particular, the influence of the addition of strontium on the electrochemical behaviour of the binary alloy (Al$\mathrm{Zn}$ ) and the results obtained are discussed.

Strontium is a soft alkaline-earth metal. Its physical and chemical properties are similar to calcium and barium. Strontium reacts vigorously with water and quickly tarnishes in air. Due to its extreme reactivity to air, this element always naturally occurs. Strontium has uses similar to those of calcium and barium, but it is rarely employed because of its higher cost. Principal uses of strontium compounds are in pyrotechnics, for the brilliant reds in fireworks and warning flares and in greases. A little is used as a getter in vacuum tubes to remove the last traces of air. Most strontium is used as the carbonate in special glass for television screens and visual display units.

\subsection{Alloy electrode preparation}

\section{Experimental Details}

$\mathrm{Al}-\mathrm{Zn}-\mathrm{Sr}$ based ternary alloy electrodes are prepared by using alloy casting method Table-1 shows the composition of alloy in terms of wt.\%. Commercially available pure aluminium (99.99\% NALCO), zinc (99.99\%) and strontium (99.9\%). The anode alloys were casted by using raw materials received from Otto Chemie Ltd. The materials were cut into pieces, weighed and melted in a graphite crucible in an automated vacuum furnace under argon atmosphere at $650^{\circ} \mathrm{C}$. The mixture was stirred gently using a carbon bar to obtain a homogeneous mixture as well as for heat dissipation. The molten alloy was poured in a preheated cast iron die of $300 \times 10 \mathrm{~mm}$, and allowed to cool in air. The obtained Al-Zn-Sr ternary alloy in the form of rod of $1 \mathrm{~cm}$ diameter x $10 \mathrm{~cm}$ long is employed for evaluation studies after machining. Actual composition of the casted alloy was determined by Atomic Absorption Spectrometer (iCE Thermo Scientific) and is given in Table I.

Table-1 Composition of Al-Zn-Sr alloy in wt. \% determined using Atomic Absorption Spectrometer (iCE Thermo Scientific).

\begin{tabular}{|l|l|l|l|l|l|l|l|}
\hline Composition & $\mathrm{Al}$ & $\mathrm{Zn}$ & $\mathrm{Sr}$ & $\mathrm{Fe}$ & $\mathrm{Cu}$ & $\mathrm{Si}$ & $\mathrm{Sn}$ \\
\hline $\mathrm{Al}$ 95\%-Zn 5\% & Remainder & 4.763 & ------ & 0.215 & 0.212 & 0.143 & 0.124 \\
\hline Al-Zn-Sr 1\% & Remainder & 4.642 & 0.725 & 0.183 & 0.126 & 0.109 & 0.134 \\
\hline Al-Zn-Sr 2\% & Remainder & 4.823 & 1.431 & 0.131 & 0.151 & 0.147 & 0.129 \\
\hline Al-Zn- Sr 3\% & Remainder & 4.652 & 2.643 & 0.142 & 0.138 & 0.203 & 0.106 \\
\hline Al-Zn- Sr 4\% & Remainder & 4.551 & 3.815 & 0.105 & 0.143 & 0.167 & 0.133 \\
\hline Al-Zn- Sr 5\% & Remainder & 4.765 & 4.344 & 0.093 & 0.124 & 0.152 & 0.125 \\
\hline
\end{tabular}

\subsection{Physico-chemical evaluation}

The Al-Zn-Sr ternary alloy of varying amount of strontium were polished using different grades of emery paper and cleaned with dilute $\mathrm{NaOH}$ followed by rinsing with distilled water. The microscopic structures such as grain size, grain boundaries and morphology of the $\mathrm{Al}-\mathrm{Zn}-\mathrm{Sr}$ alloy anodes were characterized using scanning electron microscope (Hitachi-model S-3000N). X-ray diffraction (XRD) (PAnalytical, XPert Pro using High score Plus software) study was carried out to characterize the phase structure of the prepared $\mathrm{Al}-\mathrm{Zn}-\mathrm{Sr}$ alloy.

National Conference on Current Advancements in Physics $3^{\text {rd }} \& 4^{\text {th }}$ February 2017

Department of Physics, St. John's College, Palayamkottai-627 002, Tamilnadu, India. DOI 10.9790/4861-17002024957 


\subsubsection{Determination of Galvanic efficiency}

$\mathrm{Al}-\mathrm{Zn}-\mathrm{Sr}$ alloy of varying strontium content was used as anode $\left(10 \mathrm{~cm}^{2}\right)$ and mild-steel was used as cathode (surface area $100 \mathrm{~cm}^{2}$ ). These electrodes are immersed in aerated $3 \% \mathrm{NaCl}$ solution at $28 \pm 2^{\circ} \mathrm{C}$ for a period of 96 hours under static condition as per DNV standard ${ }^{[18]}$ Different current densities were employed ca. $1.5,0.4,4.0,1.5 \mathrm{~mA} / \mathrm{cm}^{2}$ and after immersion these specimens were cleaned using a hot mixture of $20 \mathrm{~g}$ potassium dichromate and $50 \mathrm{ml}$ phosphoric acid in 1 liter water at 70 to $80{ }^{\circ} \mathrm{C}$ for 10 minutes.

Electrochemical efficiency $(\mathrm{Ah} / \mathrm{kg}) \quad \square=(\mathrm{C} \times 1000) / \square \mathbf{w} \quad \ldots$

where, $C$ is the total current impressed in $A h$ and $\square \mathrm{w}$ is the weight loss in gms

\subsubsection{Polarization studies}

Potentiodynamic polarization studies were carried out in $3.0 \% \mathrm{NaCl}$ solution under aerated condition. Saturated calomel electrode (SCE), Pt foil and Al-Zn-Sr alloy having $1 \mathrm{~cm}^{2}$ exposure area was used as reference, counter and working electrodes respectively. In order to attain equilibrium, time interval of 30-45 min was maintained and the open circuit potential (OCP) was measured before performing the potentiodynamic polarisation studies. Both anodic and cathodic polarization curves were recorded potentiodynamically using potentiostat/galvanostat (ACM instrument, UK). The corrosion kinetic parameters such as $\mathrm{I}_{\text {corr }}, \mathrm{E}_{\text {corr }}$, ba (anodic Tafel slope) and bc (cathodic Tafel slope) were measured using the built-in software (ACM inbuilt software). The following experimental conditions are maintained; sweep rate $1 \mathrm{mV} \cdot \mathrm{sec}^{-1}$, potential range - and $+200 \mathrm{mV}$ from OCP and all the experiments were carried out at a constant temperature of $28 \pm 2^{\circ} \mathrm{C}$.

\subsubsection{Self-corrosion test}

$\mathrm{Al}-\mathrm{Zn}-\mathrm{Sr}$ alloy was immersed in $3 \% \mathrm{NaCl}$ solution for a period of 15 days. The electrolyte was maintained under static condition at $28 \pm 2^{\circ} \mathrm{C}$. After exposure, the anodes were cleaned using potassium dichromate + phosphoric acid mixture at 70 to $80^{\circ} \mathrm{C}$ for 10 minutes. The anodes were rinsed in distilled water, dried and then weighed. The difference in weight before and after immersion was used to calculate the selfcorrosion.

\section{Corrosion rate $=$ Weight loss $\left(\mathrm{g} \mathrm{cm}^{-1} \mathrm{~h}^{-1}\right)$ \\ Surface area $x$ time \\ Average corrosion rate (mmpy) of Al alloy anode was calculated as}

Corrosion rate $=\left(87.6 \times 10^{4} \times W\right) /(A \times T \times D)$

where,

$$
\begin{aligned}
& T=\text { time of exposure in hours } \\
& \mathbf{A}=\text { area in } \mathrm{cm}^{2} \\
& \mathbf{W}=\text { mass loss in gms } \\
& \mathbf{D}=\text { density in } \mathrm{g} / \mathrm{cm}^{3}
\end{aligned}
$$

\subsubsection{Study of OCP and CCP variation}

While observing OCP, the potential difference between the Al-Zn-Sr alloy samples with respect to standard calomel electrode (SCE) was continuously monitored for a period of 15 days immersed in $3 \% \mathrm{NaCl}$ maintained at $28 \pm 2^{\circ} \mathrm{C}$. The closed circuit potential (CCP) of the alloy was monitored after coupling with mild steel cathodes having the surface area in the ratio of 1:10. The current density generated at the anode surface was maintained constant during CCV measurements using a controlled variable resistance ${ }^{[19]}$

\subsubsection{Study of electrochemical impedance}

Electrochemical impedance spectroscopic (EIS) study was carried out using electrochemical analyzer (ACM instrument, UK) in 3.0\% $\mathrm{NaCl}$ used as an electrolyte. SCE, $\mathrm{Pt}$ foil $2 \mathrm{~cm}^{2}$ and the $\mathrm{Al}-\mathrm{Zn}-\mathrm{Sr}$ alloy anode having $1 \mathrm{~cm}^{2}$ surface area were used as reference, counter and working electrodes respectively. The impedance analysis was carried out at the frequency range of $1 \mathrm{MHz}$ to $0.1 \mathrm{~Hz}$ with reference to OCP. Corrosion current $\left(i_{\text {corr }}\right)$, corrosion rate, solution resistance $\left(R_{\mathrm{s}}\right)$, charge transfer resistance $\left(R_{c t}\right)$ and double layer capacitance values $\mathrm{C}_{\mathrm{dl}}$ were calculated from the impedance analysis.

III. Results and discussion 


\subsection{Alloying characteristics of the anode}

Fig. 1 shows the SEM micrograph of the base alloy $(\mathrm{Al}+5 \% \mathrm{Zn})$ exhibited concrete like morphology with minimum amount of micro pores and defect structure. In all alloying composition it is mainly consisted of $\alpha$-Al matrix with precipitates of continues net work of grains. From this texture it is very difficult to understand the clear precipitation or segregation of $\mathrm{Al}+5 \% \mathrm{Zn}$ alloy matrix, which are distributed uniformly throughout the constituent. This observation revealed that the homogeneity of the base alloy is the same as it could be seen at higher magnifications also. Fig. 1.b-f shows the micrograph of strontium incorporated $\mathrm{Al}+5 \% \mathrm{Zn}$ alloy matrix in different composition. When strontium is introduced in the alloy matrix the porosity of the alloy matrix increased. Further, diffused boundaries and parts of it contains region of bright precipitate are also observed. It is projected that strontium addition leads to interdendritic porous boundaries, since it is the most insoluble metal in the $\mathrm{Al}-\mathrm{Zn}$ alloy and these precipitate is uniformly scattered along entire matrix.

Further, addition of strontium with varying content leads to refine the grains which already formed by Al-Zn constituents lead to a uniform dissolution of the alloy matrix. Zinc and strontium are more active than aluminum thus, the corrosion potential of the aluminum matrix decreases. By this higher active nature the alloying additives $\mathrm{Zn}$ and $\mathrm{Sr}$ precipitated with aluminium and rapture the film formed on the surface of grain structure and enhances the uniform dissolution. This grain refinement effect by strontium increases gradually and optimized at $5 \%$ of Sr concentration and hence of the anode efficiency obtained is maximum (99.46\%) in $5 \%$ of Sr composition.
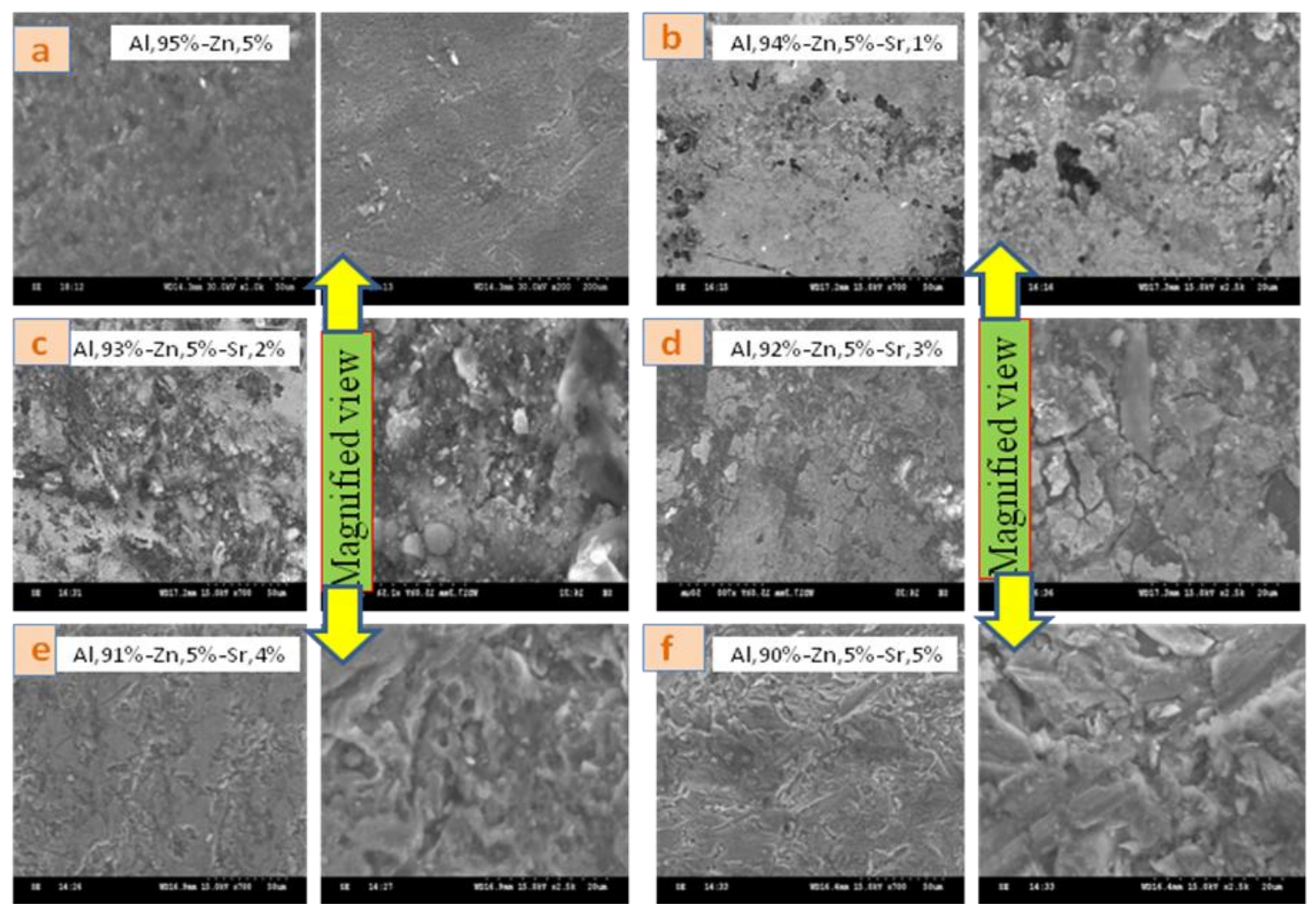

Fig.1. SEM photograph of pure $\mathrm{Al}+5 \% \mathrm{Zn}$ alloy anodes with activator (a: $0 \% \mathrm{Sr}, \mathrm{b}: 1 \% \mathrm{Sr}, \mathrm{c}: 2 \% \mathrm{Sr}, \mathrm{d}: 3 \% \mathrm{Sr}$, e: $4 \%$, and f: $5 \% \mathrm{Sr}$ ).

Further the crystal structural properties of the aluminium-zinc anode materials with varying strontium addition were characterized and confirmed by using X- ray diffraction measurement. In Fig.2, the peaks observed at around $2 \theta=38^{\circ}, 46^{\circ}$ corresponds to $\mathrm{Zn}(100)$ and (101) planes respectively. In addition to this, the peaks appeared at $2 \theta=65$ and $78^{\circ}$ is attributed to different forms of Aluminium, $\left[\alpha-\mathrm{Al}_{2} \mathrm{O}_{3}\right.$ ] with a indexing of (220) (311) respectively. Two solid solution phases $\left(\alpha\right.$ and $\beta$ ) are observed in Al-Zn binary alloy ${ }^{[20]}$. However, after the addition of $\mathrm{Sr}$ into the $\mathrm{Al}$ and $\mathrm{Zn}$ base alloy, the major peaks observed due to $\mathrm{Al}$ and $\mathrm{Zn}$ are slightly shifted, which strongly signifies the formation of intermetallic compounds. In $90 \% \mathrm{Al}-5 \% \mathrm{Zn}-5 \% \mathrm{Sr}$ alloying composition it may be possible for formation of aluminium based $\alpha$-solid solution and another phase $(\tau)$ with variable composition corresponding to $\mathrm{Al}_{2}-\mathrm{Zn}_{3}-\mathrm{Sr}_{3}{ }^{[1-23]}$. 


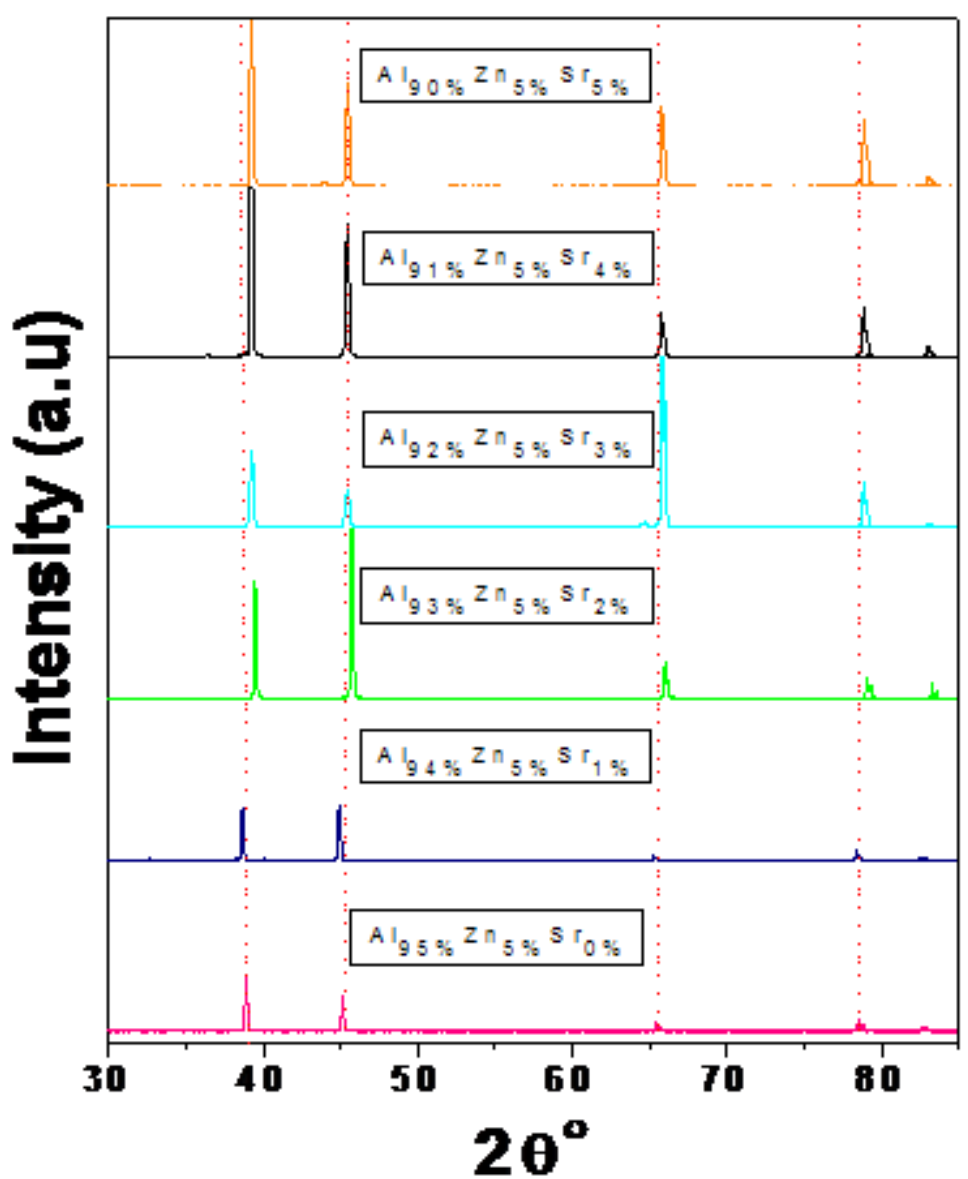

Fig.2. XRD patterns of aluminium-zinc-strontium alloy anodes.

\subsection{Evaluation of galvanic performance}

The galvanic performance of the $\mathrm{Al}+5 \% \mathrm{Zn}$ alloy anodes incorporated with different amounts of magnesium was compared in Table 2. An active CCP is desirable because a relatively positive potential shift in all current density values indicate the presence of activation. The CCP value exhibited steady performance throughout the test period at different impressed current density that indicates strontium acts as good moderator and does not hinder the polarization behaviour of the base alloy. Anodes must also possess high galvanic efficiency in order to avoid frequent anode replacement. Duplicate experiments were conducted and the average values of the efficiency obtained for 1- 5\% strontium anodes were gradually increased between $61.38-74.04 \%$, respectively and the efficiency of $\mathrm{Al}+5 \% \mathrm{Zn}$ anode was $58.42 \%$. The addition of $2 \% \mathrm{Sr}$ shifts OCP value to negative potential side than that of alloy having nil \% of Sr implies enhances the cathodic activity but this effect reduced gradually up to $5 \% \mathrm{Sr}$ denotes the adsorption of aluminium and zinc oxides on the surface of the anode. Thus the galvanic performance of anodes was much improved by the incorporation of strontium. The overall galvanic performances of strontium incorporated aluminium alloy anodes are compared. From the data it is clear that lowest self-corrosion values were observed for $1 \%$ concentration and of highest anode efficiency was in 5\% strontium incorporation. The reduction in self-corrosion values of the anodes could be attributed to the reduction in grain boundary corrosion. The strontium offered better reinforcement to the $\mathrm{Al}+5 \% \mathrm{Zn}$ alloy matrix caused very low metal dissolution during long-term exposure.

Table 4. The galvanic performance of $\mathrm{Al}+5 \mathrm{wt} \% \mathrm{Zn}$ incorporated with strontium (Electrolyte: $3 \% \mathrm{NaCl}$, temp: $28 \pm 2^{\circ} \mathrm{C}$, stagnant condition) 


\begin{tabular}{|c|c|c|c|c|c|c|c|}
\hline \multirow{2}{*}{$\begin{array}{l}\text { Amount of } \\
\text { strontium } \\
\text { added }\end{array}$} & \multirow[t]{2}{*}{$\begin{array}{l}\text { OCP V } \\
\text { vs. SCE }\end{array}$} & \multicolumn{4}{|c|}{$\begin{array}{l}\text { CCP V vs. SCE at different current } \\
\text { densities }\left(\mathrm{mA} \cdot \mathrm{cm}^{-2}\right)\end{array}$} & \multirow[t]{2}{*}{$\begin{array}{l}\text { Self-corrosion } \mathrm{x} \\
10^{-6} \mathrm{~g} \mathrm{~cm}^{-2}\end{array}$} & \multirow[t]{2}{*}{$\begin{array}{l}\text { Efficiency } \\
\quad(\%)\end{array}$} \\
\hline & & 1.5 & 0.4 & 4.0 & 1.5 & & \\
\hline 0 & -0.959 & -0.963 & -0.974 & -0.985 & -0.996 & 47.71 & 58.42 \\
\hline 1 & -0.950 & -0.970 & -0.950 & -0.937 & -0.925 & 14.83 & 62.11 \\
\hline 2 & -1.002 & -0.966 & -0.955 & -0.973 & -0.953 & 17.88 & 65.53 \\
\hline 3 & -0.975 & -0.967 & -0.954 & -0.946 & -0.942 & 49.48 & 71.0 \\
\hline 4 & -0.959 & -0.970 & -0.963 & -0.957 & -0.965 & 33.32 & 75.46 \\
\hline 5 & -0.946 & -0.985 & -0.977 & -0.957 & -0.964 & 3.49 & 99.46 \\
\hline
\end{tabular}

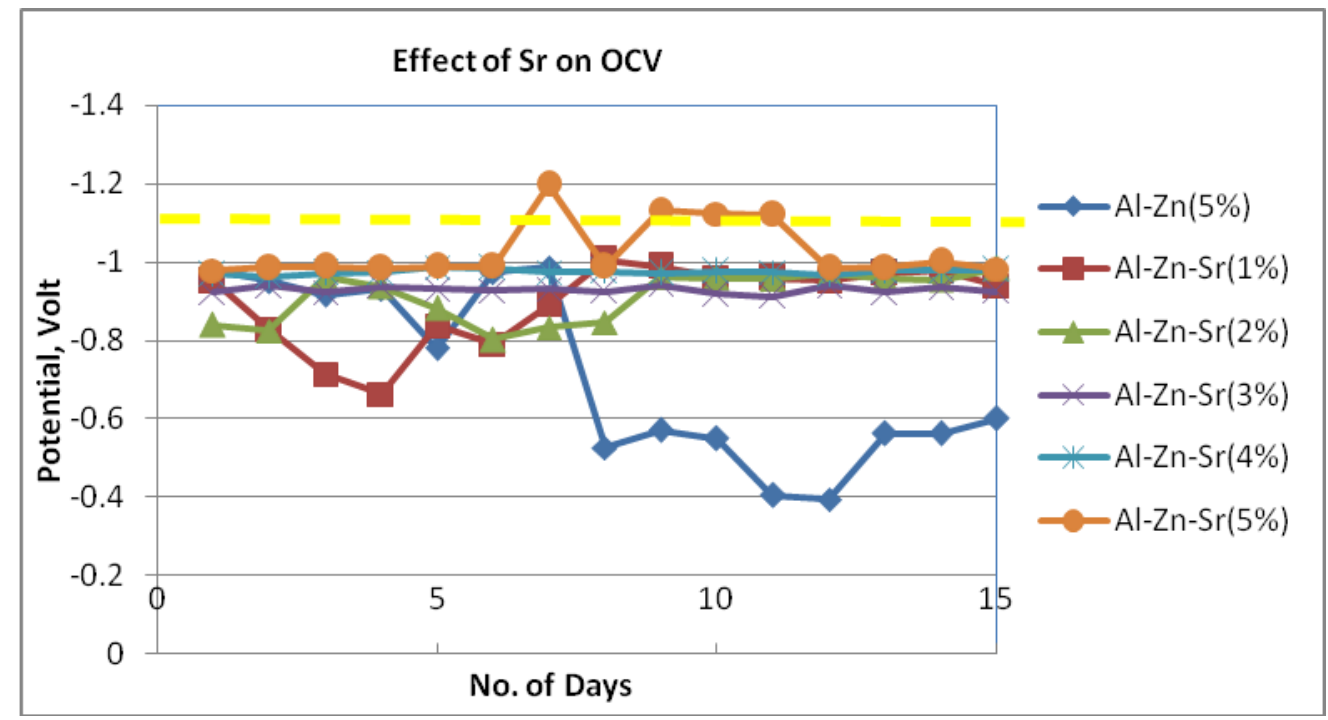

Fig.3.Effect of The calcium on OCP performance of $\mathrm{Al}+5 \mathrm{wt} \% \mathrm{Zn}$.

The effect of different concentration of strontium additive on OCP performance on A195-Zn5\% for 15 days exposed in $3 \% \mathrm{NaCl}$ electrolyte is shown in fig.3. From the fig. it is clearly indicated that in lower composition $(1 \%)$ Sr shifts OCP towards anodic potential region after seven days. But in other concentration $(2-5 \%)$ steadily withstand more or less at -1 Volt throughout entire experimental period. The minimum requirement of $\mathrm{Sr}$ is $>2 \%$ for stabilize the surface structure for long duration in marine environment. OCP cannot be considered as a sole factor for determining anodic performance, further the analysis were conducted to assess the performance of anode in detail.

\subsection{Potentiodynamic polarization}

The effect of strontium addition on the polarization behaviour of aluminium alloy anode is shown in Fig.4 and the corresponding Tafel polarization parameters derived are given in Table-3. Addition of strontium shifts the corrosion potential to more negative values, which is prerequisite of anode materials for cathodic protection systems. Introduction of strontium reduces the polarization resistance $\left(\mathrm{R}_{\mathrm{p}}\right)$ and increases the corrosion potential $\mathrm{E}_{\mathrm{corr}}$ in the negative direction. For $1 \%$ incorporated of strontium results in $\mathrm{Al}$ alloy anode, the corrosion rate is found to maximum and corrosion current values are lesser for all composition of strontium inclusion. Though the potential variations are not more than few millivolts, they can be compared and from these results, the optimum concentration of was revealed. The above results revealed that addition of 5\% strontium imparted best anode performance. The galvanic performance of anodes was much improved by the incorporation of strontium metal. 


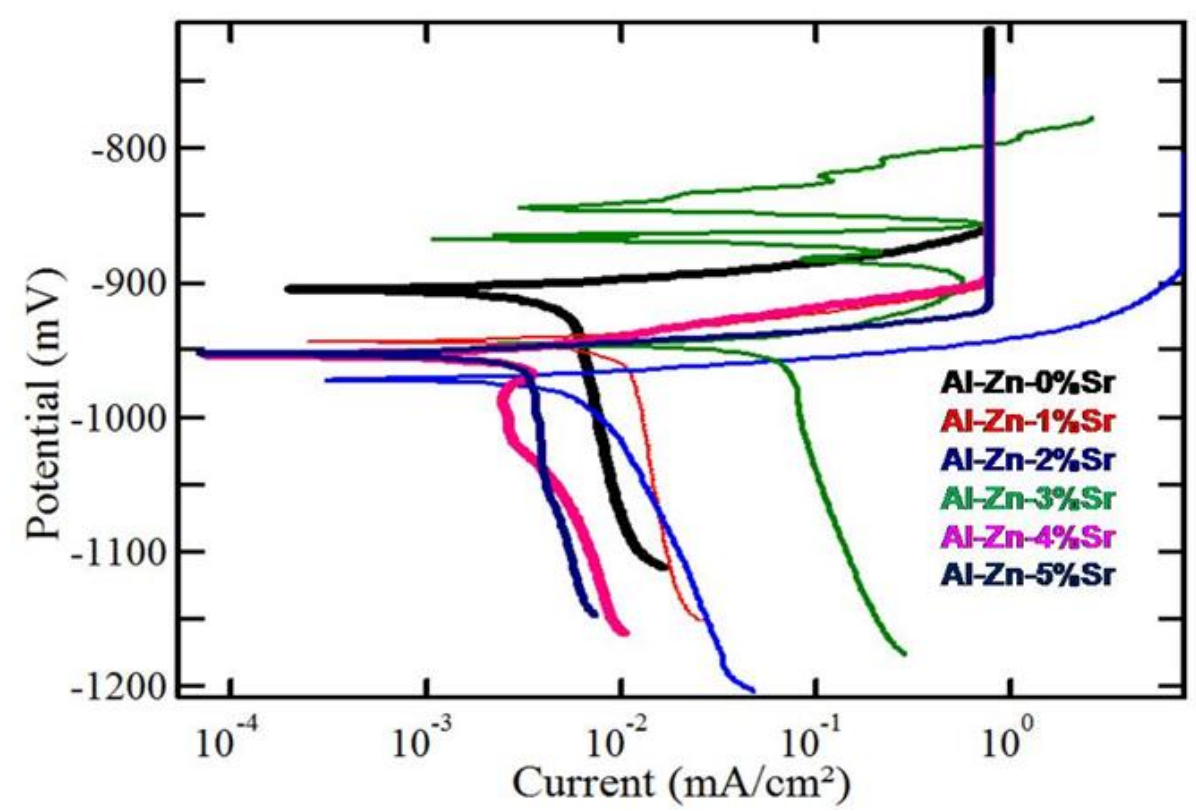

Fig.3. Polarization behavior of different composition of strontium incorporated with $\mathrm{Al}+5 \% \mathrm{Zn}$ alloy.

Table- 4. Potentiodynamic polarization parameters for different composition of strontium incorporated with

\begin{tabular}{|c|c|c|c|c|c|c|}
\hline $\begin{array}{c}\% \text { of } \\
\text { Beryllium }\end{array}$ & $\mathbf{E}_{\text {corr }}(\mathbf{V})$ & $\begin{array}{c}\mathrm{I}_{\text {corr }}\left(\mathrm{A} \cdot \mathrm{cm}^{-2}\right) \\
\quad \times 10^{-3}\end{array}$ & $\frac{b_{a}}{\left(m V / \operatorname{dec}^{-1}\right)}$ & $\begin{array}{c}\mathbf{b}_{\mathrm{c}} \\
\left(\mathrm{mV} / \operatorname{dec}^{-1}\right)\end{array}$ & $\begin{array}{c}\mathrm{Rp}(X \\
\left.\mathrm{cm}^{2}\right)\end{array}$ & $\begin{array}{l}\text { Corr. Rate } \\
\text { MPY }\end{array}$ \\
\hline 0 & -0.914 & 0.7868 & 30 & 91 & 783.2 & 0.0856 \\
\hline 1 & -0.942 & 0.008535 & 24 & 194 & 643.4 & 0.092946 \\
\hline 2 & -0.971 & 0.004260 & 14 & 129 & 552.2 & 0.0464 \\
\hline 3 & -0.950 & 0.04407 & 37 & 118 & 438.7 & 0.04799 \\
\hline 4 & -0.954 & 0.00203 & 23 & 63 & 336.5 & 0.02207 \\
\hline 5 & -0.974 & 0.001034 & 13 & 91 & 235.3 & 0.01126 \\
\hline
\end{tabular}

\subsection{Electrochemical impedance spectroscopy (EIS) measurements}

AC impedance studies were carried out to obtain information about the electrochemical and physicochemical phenomena associated with the electrode reactions during galvanic dissolution process. The EIS plots of aluminium alloy anodes incorporated with different amount of strontium are shown in Fig. 5. and the corresponding parameters derived from the analysis are tabulated in table-5. The impedance spectra of all the anodes studied in the present work have centre lies under the real axis, which is the characteristic behaviour of $\mathrm{Al}-\mathrm{Zn}$ alloys undergoing uniform galvanic dissolution ${ }^{[2]}$. The high frequency plot associated with the charge transfer process and the low frequency plot corresponds to mass transfer process. The semicircle at the high frequency was found to have similar behaviour in spite of the variation in the strontium content. The semicircle can be attributed to the formation of $\mathrm{Zn}(\mathrm{OH})_{2}$ and $\mathrm{Al}(\mathrm{OH})_{3}$ layers on the anode surface due to the oxidation of $\mathrm{Zn}$ and $\mathrm{Al}$. The depression and pseudo inductive behaviour of the semicircles can be attributed to active dissolution $^{[25]}$. Depressed semicircle shape of the complex impedance plane is due to the inhomogeneity of the anode surface ${ }^{[26]}$. The experimental data can be described using a simple equivalent circuit and in this circuit $R_{S}$ is the solution resistance, $R_{p}$ is the polarization resistance, $A$ is the constant phase element (CPE) that is introduced for better data fitting instead of an ideal capacitance parameter. The impedance expression of CPE is defined as

$\mathbf{Z}_{\mathbf{C P E}}=\left[\mathbf{A}(\mathbf{j w})^{\mathbf{n}}\right]^{-1}$,

where $A$ and $n$ are frequency independent fit parameter,

$j=(-1)^{1 / 2}$ and $w=2 \square$ f, the frequency.

Depending on the values of $n$,

the CPE can represent resistance $(n=0$ and $A=R)$,

capacitance $(\mathbf{n}=\mathbf{1}, \mathbf{A}=\mathbf{C})$,

National Conference on Current Advancements in Physics $3^{\text {rd }} \& 4^{\text {th }}$ February 2017

Department of Physics, St. John's College, Palayamkottai-627 002, Tamilnadu, India. DOI 10.9790/4861-17002024957 
inductance $(n=-1, A=L)$

and Warburg impedance $(n=0.5$ and $A=W)$.

$\mathrm{CPE}$ is related to some inhomogenities on the surface of the anodes. From the impedance analysis, the total polarization resistance $\left(R_{p}\right)$ was measure that constitutes the main practical parameter useful for the understanding of anode dissolution rate. The "double layer capacitance" in real cells often behaves like a CPE instead of like a capacitor. Number of theories have been proved to account for the non-ideal behaviour of the double layer but none has been universally accepted and in most case ' $n$ ' is treated as an empirical constant and not have much physical basis.

The analyse of $R_{p}$ value through EIS technique is the behaviour of oxide film on anode surface, which exposed in electrolyte solution. It is indication of effective interaction between the oxide film and substrate. Lower of surface resistance requisite to sacrificial anode ${ }^{(9)}$. The $\mathrm{R}_{\mathrm{p}}$ value of strontium metal incorporated alloys are in the order $0 \%<4 \%<1 \%<3 \%<5 \%<2 \%$. Minimum $\mathrm{R}_{\mathrm{p}}$ value obtained for $4 \%$ strontium metal inclusion. Experimental results implies that addition of strontium metal improve the performance of anode..

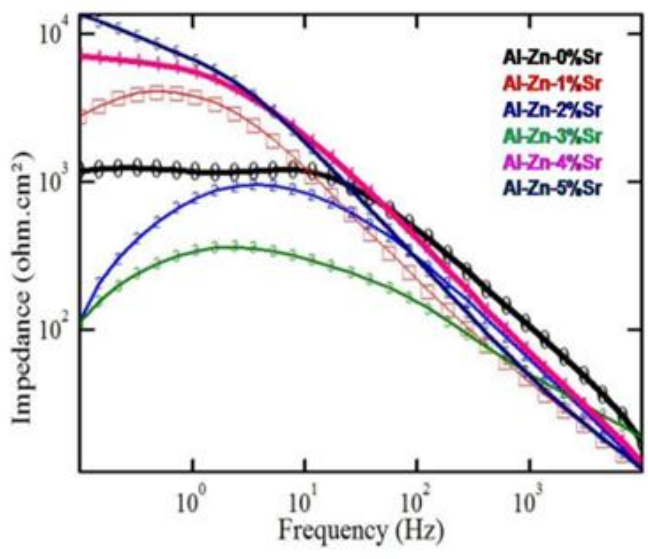

(A)

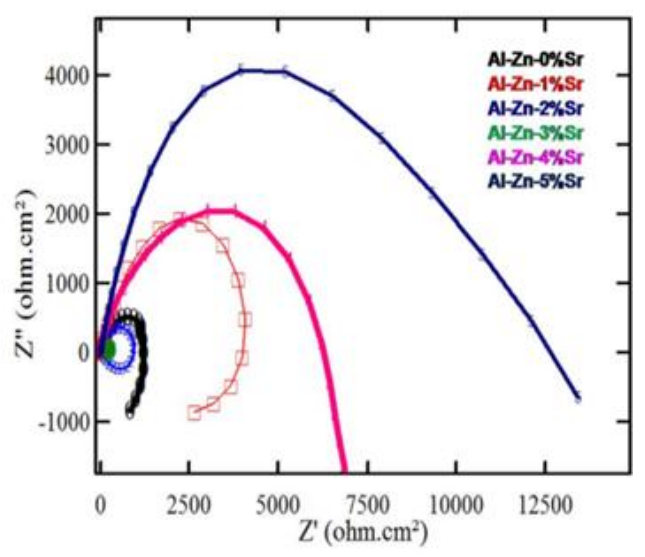

(B)

Fig. 5.(A) Nyquist and (B) Bode plots for $\mathrm{Al}-5 \% \mathrm{Zn}$ alloy with $\mathrm{Sr}$.

Table.5. Data derived from the impedance plot for strontium incorporated Al-Zn5\% alloy anode.

\begin{tabular}{|c|c|c|c|c|c|c|}
\hline \multirow[t]{2}{*}{$\%$ of Strontium } & \multicolumn{6}{|c|}{ Impedance parameters } \\
\hline & $\begin{array}{c}\mathbf{R}_{\mathbf{s}} \\
\left(\mathrm{k} \Omega . \mathrm{cm}^{2}\right)\end{array}$ & $\begin{array}{c}\mathbf{R}_{\mathrm{ct}} \\
\left(\square \mathbf{m}^{-2}\right)\end{array}$ & $\begin{array}{c}\mathbf{C}_{\mathrm{dl}} \\
\left(\square \mathbf{c m}^{-2}\right)\end{array}$ & $\begin{array}{c}R_{p} \\
\left(\Omega \mathrm{cm}^{2}\right)\end{array}$ & $\begin{array}{c}\mathrm{CPE} \\
\left(\mathrm{Fcm}^{-2}\right) \times 10^{-8}\end{array}$ & $\mathrm{n}$ \\
\hline 0 & $1.203 \times 10^{1}$ & $1.663 \times 10^{3}$ & $2.556 \times 10^{-5}$ & 80.103 & 1.074 & 1.293 \\
\hline 1 & $1.764 \times 10^{-1}$ & $9.970 \times 10^{3}$ & $7.477 \times 10^{-5}$ & 210.590 & 1.110 & 0.962 \\
\hline 2 & $1.940 \times 10^{1}$ & $4.455 \times 10^{3}$ & 3. $724 \times 10^{-5}$ & 426.946 & 1.071 & 1.116 \\
\hline 3 & $7.829 X$ & $9.99 \times 10^{2}$ & 1. $099 \times 10^{-3}$ & 214.470 & 1.043 & 0.964 \\
\hline 4 & $1.665 X$ & $3.350 \times 10^{2}$ & 3. $531 \times 10^{-4}$ & 159.210 & 1.031 & 1.261 \\
\hline 5 & $8.641 \times 10^{0}$ & $6.418 \times 10^{3}$ & $2.346 \times 10^{-5}$ & 280.389 & 1.027 & 0.953 \\
\hline
\end{tabular}

\section{Conclusions}

The metallurgical character and matrix of alloy was modified by strontium metal as modifier. Strontium addition leads to forms interdendritic porous boundaries, most insoluble metal in the Al-Zn alloy and these precipitate is uniformly scattered along entire matrix. Al-5\% Zn-5\% Sr alloying composition forms aluminium based $\alpha$-solid solution and another phase $(\tau)$ with variable composition corresponding to $\mathrm{Al}_{2}-\mathrm{Zn}_{3}-\mathrm{Sr}_{3}$. Inclusion of Sr withstand the driving potential (CCP) and shift the OCP towards more negative direction. Above $1 \%$ of $\mathrm{Sr}$ addition improve the steady OCP value throughout the experimental period and below $1 \% \mathrm{Sr}$ is not sufficient to withstand this effect. The reinforcement of strontium metal on Al-Zn5\% enhanced the efficiency from 58.42 to $99.46 \%$. The $5 \%$ strontium metal incorporated aluminium alloy exhibited excellent galvanic alloying properties and this concentration is fixed as a optimised amount. The presence of strontium in anode matrix caused effective destruction of passive $\mathrm{Ai}_{2} \mathrm{O}_{3}$ film. The destruction of passive film facilitated National Conference on Current Advancements in Physics $3^{\text {rd }} \& 4^{\text {th }}$ February $2017 \quad 56 \mid$ Page Department of Physics, St. John's College, Palayamkottai-627 002, Tamilnadu, India. DOI 10.9790/4861-17002024957 
enhancement of galvanic performance of the anode. The newly developed alloy also has merits of easy development, moderate galvanic performance and non-hazardous eco-friendly material to sea life. Still better performance of the anode could have been achieved if other metal activator or other eco-friendly metal based activators were also added along with Sr metal. The improved non-polluted eco-friendly activity of anode can be made use for formation of modified anodes suitable for use in aggressive marine environment.

\section{Acknowledgement}

One of the author, R.Natarajan acknowledged to University Grants Commission, New Delhi, India for Financial assistance.

\section{References}

[1]. Genesca, J., Juarez, J. "Development and testing of Galvanic anodes for cathodic protection", Contributios to Science. 1(3), 2000, 331-343.

[2]. Lyublinskii, E.Y., Electrochemiya,1973. 9461.

[3]. Reboul, M,, Gimenez P, Rameau J.J, (A proposed activation mechanism for Al- Zn-In anodes”, aluminium pechiney, Centre de Recherches et de Development, France1982.

[4]. Li, B,. Logan, B.E., "The impact of ultraviolet light on bacterial adhesion to glass and metal oxide-coated surface". Colloids and Surfaces B: Biointerfaces, 41(2-3) 2005, 153-161.

[5]. Shibli S.M.A, Gireesh V.S “Activation of aluminium alloy sacrificial anodes by selenium”. Corrosion Science 47(8) 2005, 2091-2097.

[6]. Munoz, A.G.,. Saidman, S.B., Bessone, J.B., "Influence of In on the corrosion of Zn-In alloys". Corrosion Science.. 43(7) 2001, 1245-1265.

[7]. Haijing Sun, Li Liu, Ying Li, Li Ma, and Yonggui Yan, The performance of Al-Zn-In-Mg-Ti sacrificial anode in simulated deep water environment, Corrosion Science_Vol. 77 Dec. 2013, 77-87.

[8]. Shibli, S.M.A., Gireesh V.S., Sony George, "Surface catalysis based on ruthenium dioxide for effective activation of aluminium sacrificial anodes" Corrosion Science. Vol. 46 (4)2004, 819-830.

[9]. Jingling Maa,b, Jiuba Wena "The effects of lanthanum on microstructure and electrochemical properties of AlZn-In based sacrificial anode alloys" Corrosion Science. 51(9) 2009, 2115-2119.

[10]. S. Khireche, D. Boughrara, A. Kadri, L. Hamadou, N. Benbrahim, "Corrosion mechanism of Al, Al-Zn and Al-ZnSn alloys in 3 wt.\% $\mathrm{NaCl}$ solution". Corrosion Science Vol. 87, Oct. 2014, 504-516.

[11]. M.A. Jingling, Wen Jiuba, L.I. Gengxin, X.V. Chunhua, "The corrosion behaviour of Al-Zn-In-Mg-Ti alloy in $\mathrm{NaCl}$ solution". Corrosion Science". 52(2) 2010, 534-539.

[12]. Mohammad R. Saeri and Ahmad Keyvani "Optimization of Manganese and Magnesium Contents in As-cast Aluminum-Zinc-Indium Alloy as Sacrificial Anode" .J. Mater. Sci. Technol., 27(9), 2011, 785-792.

[13]. H.Sina, M.Emamy, M.Saremi, A.Keyvani, M.Mahta, J.Campbell. "The influence of Ti and Zr on electrochemical properties of aluminum sacrificial anodes”. Materials Science and Engineering A,431 (1-2)2006, 263-276.

[14]. S.Gudic, I. Smoljko,M.Kliskic. "The effect of small addition of tin and indium on the corrosion behavior of aluminium in chloride solution". Journal of Alloys and Compounds, 505(1) 2010, 505, 54-63.

[15]. O. Alvarez, C. Gonzalez, G. Aramburo, R. Herrera , J.A. Juarez-Islas, "Characterization and prediction of microstructure in Al-Zn-Mg alloys'. Materials Science and Engineering A. 402 (1-2) 2005, 320-324.

[16]. Jiuba Wen, Junguan He, Xianwen Lu "Influence of silicon on the corrosion behaviour of $\mathrm{Al}-\mathrm{Zn}-\mathrm{In}-\mathrm{Mg}-\mathrm{Ti}$ sacrificial anode' Corrosion Science 53(11) 2011, 3861-3865.

[17]. J. Mathiyarasu, L.C. Nehru, P. Subramanian, N. Palaniswamy, N.S. Rengaswamy, Anti-Corros. Methods Mater. Vol. 48(5) 2001, 324-329.

[18]. DNV Recommended Practice RP B401 (1993): 'Cathodic Protection Design', Det Norske Veritas Industry AS, Hovik (1993).

[19]. NACE Standard Test Method 'Impressed Current Laboratory Testing of Aluminium Alloy Anodes', NACE Standard TM0190-98. NACE International, Houston, TX (1998).

[20]. Hawkins, D.T.; Hultgren, R.: Metals Handbook, 8th edn. Am Soc, Met, Ohio 1973.

[21]. Kuznetsov, G. M., Barsukov, A. D, Krivosheeva, G. B and Dieva, E. G, Akad, Nayk, SSSR Met.4 , $1986,198$.

[22]. A. Barbucci, G. Cerisola, G. Bruzzone, A. Saccone, Electrochim. Acta 42 (15) 1997, 2369-2380.

[23]. D.A.Petrov, in Trans alloys. VCH Weinheim, germany. (edited by G. Petzow and G.E.Effemberg. 7, $1993,57$.

[24]. T. Noguchi, P. Sawanyama, A.F. Shima, K. Hashimoto, Environ. Sci. Technol,32, 1998.3831.

[25]. Barbucci,A, Cerisola,G,. Cabot,P.L, Bruzzone.G Material Science Forum. 289, 1998, 529.

[26]. Rammelet,U., Reinhard,G. Electrochim Acta 35(6)1990, 1045-1049. 